\title{
PERAN SIZE DALAM MEMODERASI PENGARUH PROFITABILITAS, INVESMENT OPPOURTUNITY SET DAN LEVERAGE TERHADAP KEBIJAKAN DIVIDEND
}

\author{
Moeljono \\ Nasron Alfianto \\ Fakultas Ekonomi Universitas Semarang \\ sastro@usm.ac.id
}

\begin{abstract}
Dividend policy is profits which will be distributed to shareholders as dividends or retained earnings that will be retained as financing for investments in the future. There are many factors that influenced dividen policy, such as, profitability, Investment Opportunity Set (IOS), leverage, size. This study aimed to determine the influence of profitability the investment opportunity set and leverage to the cash dividend policy with Size as a moderating variabel. The object of the research is a manufacturing company that listed on the Indonesian Stock Exchange in 2009-2018 period. The selection of the sample using Purposive sampling method that samples were obtained by 19 companies. Analytical methods used to test the hypothesis is Moderated Regression Analysis (MRA). Results of this study showed that the leverage simultaneously significant effect on dividend policy with size as a moderating variable, but the probability have no significant effect on dividend policy with size as a moderating variable. Regression coefficient indicates that $13.9 \%$ of the independent variables explain the dependent variable, the remaining $84,1 \%$ is explained by other variables. Partially profitability have no significant effect to the dividend policy, while investment opportunity set and leverage have significant influence to the cash dividen policy. The Size have no able to moderate the relationship of profitability to the cash dividend policy, however Size able to moderate the relationship of leverage to the cash dividend policy.
\end{abstract}

Keywords: Profitability, Investment Opportunity Set (IOS), Leverage, Liquidity, Devidend

\section{PENDAHULUAN}

Kebijakan dividend merupakan fenomena yang komplek proses pengambilan keputusan keuangan perusahaan. Dividend merupakan distribusi laba yang diperoleh perusahaan dan dibayarkan kepada pemegang saham, dengan tujuan untuk memaksimalkan kekayaan pemilik perusahaan (pemegang saham), (Ahmad, 2019). Dividend merupakan realisasi harapan investor dan menunjukan kemampuan kinerja perusahaan, (Nathani dan Gangil, 2019), sekaligus sebagai signal perusahaan pada kondisi yang stabil dan terus berkembang (Cheng, Cullinan, \& Zhang. 2014).

Dividend merupakan salah satu kebijakan penting pada perusahaan, karena menyangkut pemegang saham yang notabene sebagai sumber modal dari perusahaan. Brigham dan Gapenski (1996), setiap perubahan kebijakan pembayaran dividend dapat memberikan dua dampak yang berlawanan. Apabila dividend dibayarkan semua, kepentingan cadangan dana terabaikan. Namun, bila ditahan semua 
maka kepentingan pemegang saham akan uang kas terabaikan. Sehingga, masalah kebijakan dividend sangat kontroversial, yakni kapan perusahaan akan membayar dividen bagi para pemegang saham, Jóźwiak (2014).

Kebijakan dividend dipengaruhi beberapa faktor. Salah satu faktor adalah laba. Profit (Laba) merupakan selisih antara penghasilan dengan beban pada satu periode akuntansi. Badu (2013), menyatakan, faktor penting dalam menentukan dan mempengaruhi kebijakan dividend adalah profitabilitas. Perusahaan dengan tingkat laba yang besar, maka semakin besar tingkat distribusi dividend yang disalurkan kepada pemegang saham. Pernyataan Badu (2013), mendukung hasil penelitian Lintner (1956), dimana beberapa faktor yang mempengaruhi kebijakan dividend adalah tingkat laba baik untuk periode saat ini maupun periode akan datang, serta mekanisme pembayaran dividend sebelumnya.

Pada umumnya perusahaan mempunyai empat tujuan dalam opersional bisnisnya, yakni: maksimalisasi profitabilitas, memaksimalkan nilai pemegang saham, memanajemen risiko sebaik mungkin, dan pendekatan ke banyak stakeholder (Anthony dan Govindarajan, 2011). Dari keempat tujuan utama tersebut, yang paling penting adalah maksimalisasi laba.

Faktor lain adalah kesempatan investasi, perusahaan yang melakukan disertifikasi investasi akan mengurangi dampak risiko financial distress dan mengatisipasi emergency ekonomi, karena perusahaan yang mampu memanfaatkan kesempatan Investasi skala tinggi, maka akan memiliki peluang pertumbuhan yang tinggi. Investment Opportunity Set (IOS) adalah nilai sebuah perusahaan yang nilainya terletak pada pengeluaran-pengeluaran yang telah ditetapkan oleh manajer perusahaan untuk masa datang, yang saat ini merupakan alternatif investasi yang diharapkan mendapat return yang lebih besar.

Sebagaian besar, perusahaan lebih mengutamakan pendanaan dari dalam yaitu laba ditahan daripada pendanaan dari luar untuk membiayai investasi karena lebih efisien. Perusahaan yang sedang tumbuh membutuhkan lebih banyak dana, akibatnya kebijakan dividend akan terpengaruh. Semakin tinggi tingkat pertumbuhan suatu perusahaan, maka semakin besar dana yang diperlukan, semakin besar pula kesempatan untuk mendapatkan keuntungan, dan semakin tinggi return earning perusahaan yang berarti semakin rendah dividend payout ratio, yang dibagikan.

Faktor lainnya adalah Kebijakan Utang (Debt to Equity Ratio). Kebijakan ini dapat mempengaruhi kebijakan dividend, dimana semakin besar tingkat utang, mengindikasikan bahwa struktur modal perusahaan lebih banyak memanfaatkan utang-utang relatif terhadap ekuitas. Pada teori statis, keputusan pendanaan berdasarkan pada struktur modal yang optimal dengan cara menyeimbangkan antara manfaat penghematan pajak atas penggunaan utang terhadap biaya kebangkrutan (Myers, 1984 dan Paskin, 1989).

Struktur modal perusahaan harus seimbangkan antara modal dari dalam dengan modal luar. Apabila manfaat penggunaan utang masih besar, bisa ditambah, namun apabila pengorbanan lebih besar, maka utang tidak bisa ditambah karena tidak lagi optimal (Myers, 1984). Sehingga, optimalnya struktur modal pada perusahaan, merupakan kombinasi antara modal sendiri dengan utang yang dapat menyeimbangkan antara risiko dan return sehingga harga saham adalah maksimum (Lumbantobing, 2008).

Semakin besar tambahan utang yang digunakan untuk mencapai stuktur modal yang optimal, maka semakin tinggi pula distribusi keuntungan yang dibagi untuk dividend. Sehingga, pembayaran dividend akan memaksa perusahaan mencari sumber pendanaan baru yang bersifat eksternal, (Crutchley dan Hansen, 1989). 
Rozeff (1982), berargumen pada tingkat utang yang tinggi akan meningkatkan biaya transaksi dan resiko perusahaan. Perusahaan dengan rasio utang tinggi akan melakukan pembayaran dengan jumlah relatif tetap kepada pihak luar. Sehingga apabila rasio tingkat utang tinggi maka pembayaran dividend akan rendah, sebagai konsekwensinya perusahaan dengan tingkat utang tinggi akan berhubungan negatif dengan pembayaran dividend.

Faktor lain yang mempengaruhi kebijakan devidend adalah ukuran perusahaan (Size). Pengklasifikasian usaha atas dasar skala operasi (besar atau kecil), merupakan indikator yang dipakai oleh investor sebagai salah satu faktor dalam menentukan keputusan investasi. Acuan indikator yang menunjukkan besar kecilnya suatu perusahaan (Size), antara lain total penjualan, rata-rata tingkat penjualan, dan total aktiva.

Perusahaan skala besar yang mempunyai akses pasar lebih baik seharusnya membagi dividend lebih tinggi, sehingga peran ukuran perusahaan dengan pembayaran dividend memiliki hubungan yang positif (Cleary, 1999 dalam Farinha, 2002). Perusahaan skala besar memiliki total aktiva yang besar, sehingga mampu menarik investor untuk menanamkan modalnya yang pada akhirnya, harga saham mampu bertahan pada hargayang tinggi.

Peran Size yang sebagai mediasi antara pengaruh ROA terhadap Kebijakan dividend, profitabilitas (ROA) pada perusahaan besar cenderung tinggi. Karena besarnya asset dan equitas guna mendukung beban operasional berbeda dengan perusahaan skala kecil yang terbatas kemampuan sumber dayanya.

Profitabilitas menjadi penentu kebijakan dividend. Semakin tinggi profit maka semakin tinggi tingkat dividend, Badu (2013). Namun, perusahaan besar juga memerlukan langkah divertifikasi usaha guna meminimalkan resiko keuangan dan antisipasi emergency ekonomi. Langkah tersebut memerlukan biaya besar, dan agar efisiens perusahaan lebih mengutamakan sumber dana internal yakni laba. Kebijakan ini akan berdampak pada laba yang akan dibagikan pada pemegang saham, sehingga profitibalitas pada perusahaan besar pembayaran dividendnya cenderung negatif.

Sedangkan Peran Size sebagai mediasi antara pengaruh DER terhadap Kebijakan dividend, Kebijakan Utang (DER) pada perusahaan besar cenderung tinggi, karena untuk mencapai struktur modal optimal. Struktur modal yang optimal akan memberikan keleluasaan bagi perusahaan dalam menentukan strategi perusahaan dan meningkatkan nilai perusahaan. Apabila nilai perusahaan meningkat maka pembayaran dividendpun cenderung meningkat. Namun, tingginya rasio utang, membuat perusahaan harus menyiapkan sejumlah kas guna pembayaran utang. sehingga tingkat utang yang tinggi berimplikasi pada rendahnya pembayaran dividend.

Fenomena perusahaan di Indonesia tentu berbeda dengan perusahaan di negara lain, karena perkembangan dan pertumbuhan perusahaan tidak bisa terlepas dari situasi dan kondisi tingkat perkonomian suatu negara. Penelitian ini dilakukan pada perusahaan manufaktur yang terdaftar di BEl rentang waktu tahun 2009-2018. Alasan pemilihan sampel, berupa perusahaan manufaktur dikarenakan perusahaan yang paling dominan terdaftar di BEI dan paling banyak membagikan dividend.

Sejauh ini penelitian yang berkaitan dengan kebijakan dividend telah banyak dilakukan. Diantaranya adalah variabel Profitabilitas yang di proksi oleh ROA pada penelitian Ariandani dan Yadnyana (2016), Bostanci, Kadioglu \& Sayilgan (2018), dan Mubarok (2013) berpengaruh terhadap kebijakan dividend sedangkan penelitian Kristanti \& Fitrianingsih (2016), Rizqia, Aisjah, and Sumiati (2013), M Kannadhasan, et.al (2017), Dąbrowska, Sawicka \& Ulrichs (2019), Maladjian \& Khoury (2014), dan 
Rafindadi and Bello. (2019). ROA tidak berpengaruh signifikan terhadap kebijakan dividend.

Variabel IOS pada penelitian Kristanti \& Fitrianingsih (2016), Rizqia, Aisjah, dan Sumiati (2013), Bostanci, Kadioglu \& Sayilgan (2018), dan Rafindadi and Bello. (2019), menyatakan bahwa IOS memiliki pengaruh terhadap kebijakan dividend, namun hasil penelitian Ariandani dan Yadnyana (2016), dan Ravichandran (2011), variabel IOS tidak berpengaruh terhadap kebijakan devidend.

Sedangkan Leverage yang di proksi oleh DER pada penelitian M Kannadhasan, et al (2017), dan Maladjian \& Khoury (2014), memiliki pengaruh terhadap kebijakan dividend sedangkan hasil penelitian Rizqia, Aisjah, dan Sumiati (2013), Mubarok (2016) dan Bostanci, Kadioglu \& Sayilgan (2018), variabel DER tidak berpengaruh terhadap kebijakan dividend. Variabel Size pada penelitian Bostanci, Kadioglu \& Sayilgan (2018), Dąbrowska, Sawicka \& Ulrichs (2019) dan Maladjian \& Khoury (2014), berpengaruh terhadap kebijakan dividend akan tetapi pada penelian Rizqia, Aisjah, dan Sumiati (2013), M Kannadhasan, et.al (2017), dan Rafindadi dan Bello, (2019), tidak berpengaruh terhadap kebijakan dividend.

Beberapa penelitian tersebut menunjukan hasil yang tidak konsisten, sehingga penelitian ini dilakukan. Perbedaan penelitian ini dengan penelitian oleh Ariadani dan Yadnyana (2016) dan Kritanti dan Fitrianingsih (2013) adalah mengubah variabel moderasi dari likuiditas yang diproksikan dengan cash ratio menjadi Size, karena temuan dalam penelitian terdahulu membuktikan bahwa likuiditas tidak mampu memoderasi pengaruh profitabilitas dan IOS pada kebijakan dividend. Penelitian ini dilakukan pada perusahaan manufaktur yang terdaftar di BEl rentang waktu tahun 2009-2018. Dipilinnya variabel Size sebagai moderating diharapkan akan mampu memperkuat peran variabel ROA, IOS dan DER terhadap kebijakan dividend.
Sektor manufaktur dipilih karena merupakan jumlah sektor yang paling banyak terdaftar di BEI bila dibandingkan sektor lain. Selain itu sektor manufaktur yang paling banyak membagikan dividend (Mayangsari, 2015) dan (Ariandani dan Yadnyana, 2016).

Penelitian ini bertujuan mengkaji kembali pengaruh rasio-rasio keuangan terhadap kebijakan dividend yang di proksi dengan DPR. Pada penelitian ini rasio profitabilitas diproksikan dengan variabel ROA, IOS diproksikan dengan MBVE, Leverage diproksikan dengan variabel DER, sedangkan untuk memperkuat ataupun memperlemah variabel independen tersebut terhadap variabel dependen dengan menambah rasio Size yang diproksikan dengan natural logaritma nilai pasar ekuitas perusahaan pada akhir tahun yaitu jumlah saham yang beredar pada akhir tahun dikali dengan harga pasar saham akhir tahun.

\section{KAJIAN PUSTAKA}

\section{Teori Kebijakan Deviden}

Berikut beberapa teori kebijakan devidend.

1. Dividend Policy Irrelevance (Miller dan Modigliani, 1961)

Konsep dasar teori ini adalah bahwa kebijakan dividend tidak logis, karena tidak memiliki pengaruh pada nilai perusahaan atau biaya modalnya. Nilai perusahaan ditentukan pada kebijakan investasi, bukan pada laba yang dibagi atau ditahan.

Teori ini didasari pada pemikiran: bahwa kebijakan investasi dan utang telah melalui perencanaan, maka tidak akan berpengaruh pada pembayaran dividend, dan pasar modal yang sempurna diasumsikan ada.

2. Clientele Effects Hypothesis

Dasar konsep teori ini perusahaan menerapkan adanya kebijakan dividend khusus, dengan harapan akan menarik sekumpulan peminat atau clientele yang terdiri dari para investor yang menyukai 
kebijakan dividend khusus tersebut. Hal ini, disebabkan sebagaian investor, lebih menyukai pendapatan saat ini dibandingkan dengan kenaikan nilai modal pada masa datang, sehingga investor menghendaki agar perusahaan membagikanya sebagaian.

Disisi lain, investor kurang menyukai return dari investasi pada periode berjalan, tetapi mereka akan menginvestasikan kembali pendapatan dividend yang diterima setelah dikurangi pajak penghasilan, sehingga investor akan mendapat bagian dividend yang rendah. Kondisi ini oleh Miller \& Modigliani disebut sebagai clientele effect, yang diharapkan dapat menolong untuk menjelaskan mengapa harga saham berubah sesudah diumumkannya perubahan kebijakan dividend.

\section{Signaling Hypothesis}

Konsep teori ini, pimpinan perusahan lebih banyak menghetahui kondisi perusahaan yang sebenarnya, dibandingkan dengan pemegang saham atau investor. Sehingga, pembagian dividend digunakan sebagai salah satu cara untuk berkomunikasi yang isinya berupa informasi yang tidak diketahui oleh pasar. Pada Teori ini ada asumsi bahwa kebijakan dividend terlihat penting, namun sebab akibat yang sesungguhnya tidak dapat diketahui.

Sehingga investor akan memandang bahwa adanya perubahan pada pembayaran dividend merupakan tanda kondisi keuangan perusahaan yang sebenarnya, bagaimana kemampun perusahaan dalam meraih laba. Dengan demikian, naiknya pembayaran dividend yang lebih besar dari yang diharapkan, mengisyaratkan bahwa perusahaan mempunyai kemampuan untuk meningkatkan keuntungannya. Begitu pula sebaliknya, bila terjadi penurunan pembayaran dividend, menandakan perolehan keuntungan perusahaan menurun.
Argumen dari teori ini di bangun atas dasar pada information asymmetry antara manajer (insiders) dan investor dari luar (outsider), dimana para manajer memiliki informasi lebih lengkap mengenai kinerja saat ini dan harapan keuntungankeuntungan pada masa datang, yang tidak dimiliki oleh outsiders. Dengan, demikian, manajer memiliki inisiatif untuk berkomunikasi dan menyampaikan informasi kepada pasar, dengan harapan adanya pembayaran dividend dapat digunakan sebagai alat pemberi isyarat untuk mempengaruhi harga saham. Maka, suatu pengumuman perubahan kenaikkan dividend akan membawa berita baik sehingga reaksi harga saham akan naik, atau sebaliknya.

4. Bird In Hand Theory

Gordon \& Lintner (1963) dengan Bird in the Hand Theory, berpendapat bahwa dividend lebih baik dari pada capital gain, karena memiliki resiko rendah, seharusnya perusahaan memberikan rasio pembayaran dividend yang tinggi dengan menawarkan dividend yield yang tinggi agar dapat memaksimalkan harga saham. Adanya keyakinan bahwa kebijakan dividend tidak penting secara implisit mengasumsikan bahwa investor menggunakan required rate of return yang sama, baik pendapatan berupa dividend maupun capital gain. Namun pendapatan dividend memiliki sifat yang lebih pasti (predictable) daripada capital gain.

Pihak manajemen bisa mengontrol dividend, namun, tidak bisa mempengaruhi harga saham di pasar modal. Hal ini, menandakan bahwa tingkat risiko capital gain lebih besar. Oleh sebab itu, rate of return digunakan ketika mendiskon capital gain harus lebih tinggi dari yang digunakan terhadap pendapatan dividend.

5. Tax Preference

Tax preferency theory dari Farrar \& Slewyn (1967) dan Brennan (1970) 
menjelaskan bahwa pemegang saham lebih menyukai retained earnings daripada dividend, karena adanya pertimbangan pajak. Konsep teori ini agar perusahaan membayar dividend yang rendah jika ingin memaksimalkan harga saham.

Farrar \& Slewyn (1967) dan Brennan (1970) menerangkan bahwa kebijakan yang terbaik adalah tidak membayar dividend sama sekali, investor lebih baik menjual saham beberapa lembar, dan membayar pajak keuntungan, karena modalnya lebih rendah.

Investor bertujuan memaksimalkan tingkat hasil investasi setelah dipotong pajak tanpa harus menanggung risiko yang lebih besar, hal ini dilakukan dengan cara merealisasi seminimal mungkin tingkat pajak efektif atas pendapatan dan sedapat mungkin menunda pembayaran pajak.

6. Teori Dividend Residual

Prinsip Teori ini adalah ketika perusahaan akan membayar dividend harus memperhatikan berapa banyak uang kas yang dibagikan, ada dua hal yang harus diperhatikan, yakni: (1) meningkatkan nilai pemegang saham, dan (2) arus kas yang dihasilkan perusahaan adalah milik pemegang saham (Brigham dan Houston, 2001). Manajemen harus menahan diri dengan upaya menahan laba kecuali jika laba itu dapat diinvestasikan kembali guna menghasilkan return yang lebih tinggi dan ikut dirasakan oleh pemegang saham. Dengan demikian, ekuitas internal, laba ditahan, lebih rendah biaya modalnya daripada ekuitas eksternal. Kondisi ini mendorong perusahaan untuk menahan laba karena menambah ekuitas internal dan mengurangi menambah ekuitas eksternal di masa mendatang untuk mendanai investasinya. Adanya biaya penerbitan saham baru memperlihatkan perbedaan antara modal internal dan eksternal. Tanpa biaya penerbitan, perusahaan tidak kesulitan dalam menentukan jumlah dividend dan laba ditahan, termasuk didalamnya jumlah pendanaan eksternal.

Adanya biaya penerbitan saham baru, perusahaan akan mengutamakan pendanaan internal. Sehingga, perusahaan akan membayar dividend setelah dana kebutuhan investasi terpenuhi; apabila ada "pendapatan sisa" atau residual, barulah dividen dibayarkan. (Martin et al., 1994).

\section{Profitabilitas}

Profitabilitas merupakan kemampuan perusahaan dalam menghasilkan laba dengan menggunakan sumber daya milik perusahaan, seperti aktiva, modal, atau penjualan (Sudana, 2011). Rasio ini untuk menilai kemampuan perusahaan dalam mencari keuntungan, Kasmir (2014). Hubungan antara profitabilitas dengan kebijakan dividend adalah, ketika semakin tinggi tingkat profit perusahan yang dihasilkan maka semakin besar tingkat dividend yang dibagikan kepada pemagang saham.

Hal ini sejalan dengan pendapat Badu (2013), menyatakan profitabilitas telah menjadi penentu dari kebijakan dividend selama bertahun-tahun, dan menjadikan profitabilitas sebagai faktor penting dalam mempengaruhi kebijakan dividend. Semakin tinggi tingkat laba maka semakin besar tingkat pembayaran dividend yang dibagikan kepada pemegang saham. Mubarok (2016) Apabila perusahan semakin besar profitabilitasnya (ROA) maka semakin besar devidend yang akan dibagikan, Dengan demikian semakin tinggi ROA maka, DPR perusahaan tersebut bernilai positif.

Sesuai dengan theory bird in the hand sebagimana dijelakan Brigham dan Daves (2003), menyatakan bahwa investor lebih memilih pembagian devidend. Hal ini karena investor ingin meningkatkan nilai perusahaan dan profitabilitas dari laba tersebut. Sehingga profit perusahaan akan baik. Pendapat tersebut sesuai hasil penelitian 
(Mubarok, 2016) dan (Bostanci, Kadioglu \& Sayilgan, 2018), yang menunjukkan bahwa profitabilitas berpengaruh signifikan terhadap kebijakan dividend. Berdasarkan uraian tersebut maka dapat dirumuskan hipotesis:

H1: ROA berpengaruh terhadap kebijakan dividend

\section{Invesment Oppourtunity Set}

Istilah IOS pertama kali diperkenalkan Myers (1977) yang menguraikan perusahaan sebagai suatu kombinasi antara aktiva riil (assets in place) dan opsi investasi di masa depan. Hartono (2003), kesempatan Investasi menggambarkan tentang luasnya kesempatan atau peluang investasi bagi suatu perusahaan. IOS merupakan nilai perusahaan yang besarnya tergantung pada pengeluaran yang ditetapkan manajemen di masa yang akan datang. Bagi perusahaan yang tidak dapat menggunakan kesempatan investasi tersebut akan mengalami suatu pengeluaran yang lebih tinggi dibandingkan dengan nilai kesempatan yang hilang (Ahmad, 2009).

Hubungan antara kesempatan investasi (IOS) dengan kebijakan dividend dapat diasumsikan, ketika suatu perusahaan menggunakan dana yang ada untuk berinvestasi terlebih dahulu daripada membayar dividend, maka perusahaan cenderung membagikan dividend yang kecil. Hasil penelitian Rizqia, Aisjah, Sumiati (2013), Bostanci, Kadioglu and Sayilgan (2018) dan Rafindadi and Bello (2019). membuktikan bahwa pengaruh IOS menunjukkan pengaruh yang signifikan terhadap pertumbuhan ekuitas. Pertumbuhan perusahaan merupakan harapan yang diinginkan oleh pihak internal maupun pihak eksternal perusahaan. Berdasarkan uraian tersebut maka dapat dirumuskan hipotesis penelitian adalah:

$\mathrm{H} 2$ : IOS berpengaruh terhadap Kebijakan Dividend

\section{Leverage}

Rasio Leverage merupakan rasio yang digunakan untuk mengukur sampai sejauh mana aktiva perusahaan dibiayai oleh utang (Kasmir, 2014). DER adalah rasio yang digunakan untuk mengukur proporsi dana yang bersumber dari utang untuk membiayai aktiva perusahaan (Sudana, 2011).

Penelitian M Kannadhasan, et al (2017). Bostanci, Kadioglu and Sayilgan (2018). Dąbrowska, Sawicka \& Ulrichs (2019): dan Maladjian \& Khoury (2014), membuktikan bahwa DER menunjukkan pengaruh positif signifikan terhadap DPR. Tingkat utang akan mempengaruhi struktur modal. Modal yang optimal merupakan harapan manajemen untuk meningkatkan kinerja perusahaan dalam perolehan laba. Laba yang meningkat pada akhirnya akan dikembalikan kepada pemilik perusahaan (pemegang saham). Dengan demikian kebijakan utang mempengaruhi kebijakan devidend. Berdasarkan uraian tersebut maka dapat dirumuskan hipotesis penelitian adalah:

H3: Leverage berpengaruh terhadap Kebijakan Dividend

\section{Pengaruh Profitabilitas terhadap Kebi- jakan Dividend, dimoderasi Size}

Perusahaan besar mampu meraih profitabilitas (ROA) yang tinggi, karena besarnya asset dan equitas untuk mendukung operasionalnya berbeda dengan perusahaan skala kecil yang terbatas kemampuan sumber dayanya. Selama ini profitabilitas menjadi penentu kebijakan devidend. Semakin tinggi tingkat laba maka semakin besar tingkat pembayaran dividend yang dibagikan kepada pemegang saham.

Namun, perusahaan besar memerlukan langkah divertifikasi usaha guna meminimalkan resiko keuangan dan antisipasi emergency ekonomi. Langkah tersebut memerlukan biaya besar, dan untuk efisiensi perusahaan lebih mengutamakan 
sumber daya internal yakni dari laba. Kebijakan ini akan berdampak pada laba yang akan dibagikan pada pemegang saham, sehingga profit perusahaan besar pembayaran devidend cenderung negatif.

Tetapi, pada perusahaan dengan skala besar akan mampu menolak hipotesis ini. Perusahaan yang mampu membukukan profit yang tinggi diperkuat dengan besarnya ukuran perusahaan, maka perusahaan mampu meraih keuntungan yang tinggi, sehingga devidend yang dibagikan cenderung besar. Berdasarkan uraian diatas maka hipotesis yang dikembangkan sebagai berikut:

H4: Profitabilitas berpengaruh terhadap Kebijakan Dividend dimoderasi Size

\section{Pengaruh Leverage terhadap Kebijakan Dividend, yang dimoderasi Size}

Pada perusahaan yang mempunyai rasio tingkat utang tinggi cenderung membagikan devidend yang relatif rendah karena perusahaan harus menyediakan sejumlah kas yang relatif permanen untuk membayar utang. Namun, bagi perusahaan yang besar akan mampu memperlemah hipotesis tersebut.

Karena perusahaan yang relatif besar mempunyai asset yang besar untuk menjamin semua utang-utang perusahaan. Maka, semakin besar ukuran perusahaan, semakin besar pula ketersediaan kas perusahaan sehingga semakin besar pula dividend yang akan dibayarkan perusahaan. Berdasarkan uraian tersebut maka hipotesis yang dikembangkan adalah:

H5: Leverage berpengaruh Terhadap Kebijakan Dividend dimoderasi Size

\section{METODE PENELITIAN}

Jenis penelitian ini penelitian kuantitatif, yang didasarkan pada pengukuran kuantitas atau jumlah dan berlaku untuk fenomena yang dapat dinyatakan dalam segi kuantitas, (Sugiyono, 2013).

Pengunaan penelitian kuantitatif untuk menganalisis hubungan antara variabel- variabel dalam penelitian terutama karena variabel disajikan dalam jumlah.

\section{Populasi dan Sampel}

Populasi dalam penelitian ini adalah seluruh perusahaan manufaktur yang terdaftar di BEI rentang waktu tahun 20092018 sejumlah 158 perusahaan. Sedangkan pemilihan sampel menggunakan teknik purposive sampling, dengan kriterea: 1 . Perusahaan menerbitkan laporan keuangan per 31 Desember dalam mata uang Rupiah dari tahun 2009-2018. 2. Perusahaan yang sahamnya diperdagangkan secara aktif di BEI. 3. Perusahaan yang 10 tahun berturutturut dari tahun 2009-2018 membagikan dividend. 4. Menampilkan data dan informasi yang digunakan sebagai analisis faktor-faktor yang mempengaruhi kebijakan dividend.

Setelah dilakukan seleksi, diperoleh 19 perusahaan yang memenuhi kriteria, sehingga didapatkan data sebanyak 190 data perusahaan (19X10). Selanjutnya daftar perusahaan yang menjadi sampel penelitian adalah:

\section{Tabel 1}

\section{Daftar Perusahaan Sampel}

\begin{tabular}{lll}
\multicolumn{1}{c}{ No } & Kode & \multicolumn{1}{c}{ Perusahaan } \\
\cline { 2 - 3 } 1 & INTP & Indocement Tunggal Prakasa Tbk \\
2 & SMGR & Semen Indonesia Persero \\
3 & AMFG & Asahimas Flat Glass Tbk \\
4 & ARNA & Arwana Citramulia Tbk \\
5 & LION & Lion Metal Works Tbk \\
6 & LMSH & Lionmesh Prima Tbk \\
7 & EKAD & Ekadharma International Tbk \\
8 & ASII & Astra International Tbk \\
9 & AUTO & Astra Otoparts Tbk \\
10 & SMSM & Selamat Sempurna Tbk \\
11 & SCCO & Supreme Cable Manufacturing \\
& & Corporation Tbk \\
12 & DLTA & Delta Djakarta Tbk \\
13 & INDF & Indofood Sukses Makmur T bk \\
14 & MYOR & Mayora Indah Tbk \\
15 & GGRM & Gudang Garam Tbk \\
16 & HMSP & Hanjaya Mandala Sampoerna Tbk \\
17 & DVLA & Darya Varia Laboratoria Tbk \\
18 & KLBF & Kalbe Farma Tbk \\
19 & MERK & Merck Indonesia Tbk \\
\hline \multirow{2}{*}{ Sumber: www.idx.co.id }
\end{tabular}

\section{Sumber: www.idx.co.id}

Jenis data yang digunakan sekunder yang berupa laporan keuangan perusahaan 
sampel yang dilaporkan ke BEI dari tahun 2009-2018. Sumber yang digunakan laporan keuangan yang terdapat pada ICMD (Indonesian Capital Market Directory) dan website Indonesia Stock Exchange (www. idx.co.id) selama periode tahun 2009-2018.

Penelitian ini terdapat 5 variabel, yakni satu variabel dependen ( $Y$ ) kebijakan devidend (DPR) dan tiga variabel independen profitabilitas (ROA), IOS (MBVE), leverage $(D E R)$ serta satu variabel moderasi Size.

$$
\begin{aligned}
& \text { DPR }=\frac{\text { Dividend Per Lembas Saham }}{\text { Laba Per Lembar Saham }} \\
& \text { ROA }=\frac{\text { Laba Bersih Setelah Pajak }}{\text { Total Aset }} \\
& \text { MBVE }=\frac{\text { Saham Beredar } \text { X Harga Penutupan }}{\text { Total Ekuitas }} \\
& \text { DER }=\frac{\text { Total Utang }}{\text { Total Ekuitas }}
\end{aligned}
$$$$
\text { SIZE = Log natural of total assets }
$$

\section{Kerangka Pemikiran}

Berdasarkan fenomena gap dan hasil penelitian terdahulu maka, digambarkan bentuk kerangka pemikirannya adalah sebagai berikut:

\section{Gambar 1}

\section{Model Kerangka Pemikiran}

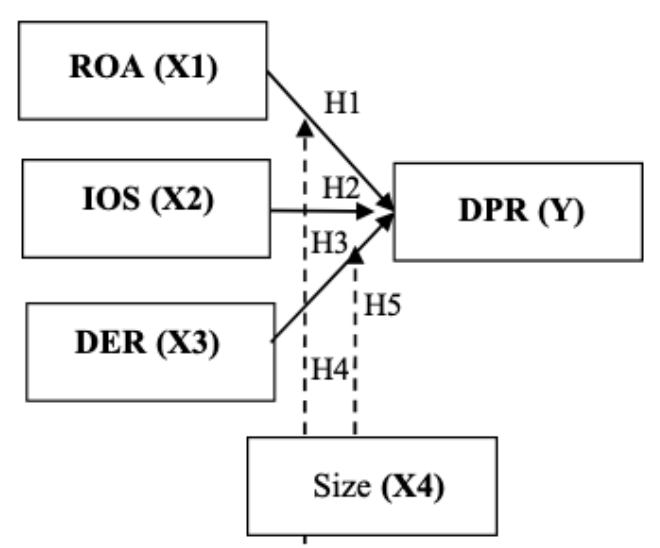

Sumber: Berbagai penelitian dikembangkan (2019)

\section{METODE PENELITIAN}

Metode Analisis yang digunakan adalah statistik deskriptif, uji asumsi klasik, regresi linier berganda, dan uji interaksi Moderated Regression Analysis (MRA), sehingga model regresi dirumuskan dengan persamaan berikut:

Persamaan Regresi Model I :

$$
Y=a+b_{1} X_{1}+b_{2} X_{2}+b_{3} X_{3+} e
$$

Persamaan Regresi Model II :

$Y=a+b_{1} X_{1}+b_{2} X_{2}+b_{3} X_{3}+b_{4} X_{4}+b_{5}\left(X_{1}{ }^{*} X_{4}\right)$

$$
+b_{6}\left(X_{3}^{*} X_{4}\right)+e
$$

Keterangan :

$$
\begin{array}{ll}
\mathrm{Y} & : \text { Kebijakan Dividen (DPR) } \\
\mathrm{a} & : \text { konstanta } \\
\mathrm{b}_{1}-\mathrm{b}_{5} & : \text { koefisien regresi } \\
\mathrm{X}_{1} & : \text { Profitabilitas (ROA) } \\
\mathrm{X}_{2} & : \text { IOS (MBVE) } \\
\mathrm{X}_{3} & : \text { Leverage (DER) } \\
\mathrm{X}_{4} & : \text { Size } \\
\mathrm{X}_{1}{ }^{*} \mathrm{X}_{4} & : \text { Interaksi antara ROA dengan } \\
& \text { Size } \\
\mathrm{X}_{3}{ }^{*} \mathrm{X}_{4} & : \text { Interaksi antara DER dengan } \\
& \text { Size } \\
\mathrm{e} & : \text { error }
\end{array}
$$

\section{HASIL PENELITIAN DAN PEMBAHASAN} Analisis Data \& Statistik Deskriptif

Pengujian dilakukan dengan menggunakan bantuan software SPSS 23 , adapun hasil uji statistik deskriptif, ada pada tabel 1.

Penjelasan terhadap variabel adalah:

\section{Variabel Independen}

1) Variabel $R O A / X_{1}$ menunjukkan nilai terendah 0,013 perusahaan secara keseluruhan mampu menghasilkan laba bersih $13 \%$, dengan dukungan total asetnya. Sedangkan nilai tertinggi 1,621 , perusahaan secara keseluruhan mampu mencapai laba bersih $162,5 \%$ yang didukung total aset. Rata-rata ROA 0,190 perusahaan dalam menghasilkan keuntungan dengan jumlah keseluruhan aktiva yang tersedia dalam perusahaan rata-rata kecil. Sedangkan standar deviasi 0,209 
Tabel 2

Descriptive Statistics

\begin{tabular}{lcrrrr}
\hline & N & \multicolumn{1}{c}{ Min } & \multicolumn{1}{c}{ Max } & \multicolumn{1}{c}{ Mean } & $\begin{array}{c}\text { Std. } \\
\text { Deviation }\end{array}$ \\
\hline Y & 190 &, 023 &, 999 &, 444 &, 2813 \\
\hline X1 & 190 &, 013 & 1,621 &, 190 &, 2090 \\
\hline X2 & 190 &, 080 & 22,291 & 3,426 & 3,5507 \\
\hline X3 & 190 &, 011 & 1,803 &, 534 &, 3798 \\
\hline X4 & 190 & 25,011 & 33,473 & 29,141 & 2,0157 \\
\hline $\begin{array}{l}\text { Valid N } \\
\text { (listwise) }\end{array}$ & 190 & & & & \\
\hline \multicolumn{5}{r}{ Sumber: Output SPSS, data sekunder yang diolah, 2019}
\end{tabular}

Tabel 3

Hasil Uji Normalitas One-Sample Kolmogorov-Smirnov Test

\begin{tabular}{|c|c|c|}
\hline & & $\begin{array}{r}\text { Unstandardized } \\
\text { Residual }\end{array}$ \\
\hline \multicolumn{2}{|l|}{$\mathrm{N}$} & 190 \\
\hline \multirow{3}{*}{ Normal Parameters ${ }^{a, b}$} & Mean & 0,00000000 \\
\hline & $\begin{array}{l}\text { Std. } \\
\text { Deviation }\end{array}$ & 0,2911666 \\
\hline & Absolute & 0,059 \\
\hline \multirow{2}{*}{$\begin{array}{l}\text { Most Extreme } \\
\text { Differences }\end{array}$} & Positive & 0,027 \\
\hline & Negative & $-0,059$ \\
\hline \multicolumn{2}{|l|}{ Test Statistic } & 0,059 \\
\hline \multicolumn{2}{|l|}{ Asymp. Sig. (2-tailed) } &, $200^{\mathrm{c}, \mathrm{d}}$ \\
\hline \multicolumn{3}{|c|}{ a. Test distribution is Normal. } \\
\hline \multicolumn{3}{|l|}{ b. Calculated from data. } \\
\hline \multicolumn{3}{|c|}{ c. Lilliefors Significance Correction. } \\
\hline \multicolumn{3}{|c|}{ d. This is a lower bound of the true significance. } \\
\hline
\end{tabular}

menunjukkan data tidak bervariasi penyebarannya.

2) Variabel $M B V E / X_{2}$ menunjukkan nilai terendah 0,808 kesempatan investasi perusahaan secara keseluruhan minimal $8,08 \%$, dan tertinggi $2229 \%$. Rata-rata MBVE senilai 3,426 , rata-rata kesempatan investasi perusahaan secara keseluruhan tinggi. Sedangkan nilai standar deviasi 3,550, yang lebih besar dari nilai rata-rata menunjukan variabel MBVE memiliki data ekstrem yang mengakibatkan variabel berpengaruh secara signifikan terhadap variabel dependen.

3) Variabel $\mathrm{DER} / \mathrm{X}_{3}$ menunjukkan nilai ter- endah 0,112, perusahaan secara keseluruhan menggunakan kebijakan hutang $1,12 \%$ dan tertinggi $18,03 \%$ untuk membayar deviden. Rata-rata DER senilai 0,534 menunjukan perusahaan secara keseluruhan memanfaatkan kebijakan hutang untuk membayar deviden 53,4\%. Sedangkan nilai standar deviasi 0,379 $(37,9 \%)$ yang lebih kecil dari nilai ratarata menunjukkan data tidak bervariasi penyebarannya.

\section{Variabel Moderasi}

Hasil yang diperoleh dari Size pada perusahaan sampel secara keseluruhan, 
Tabel 5

Hasil Uji Heteroskedastisitas - Uji Glejser

Coefficients $^{a}$

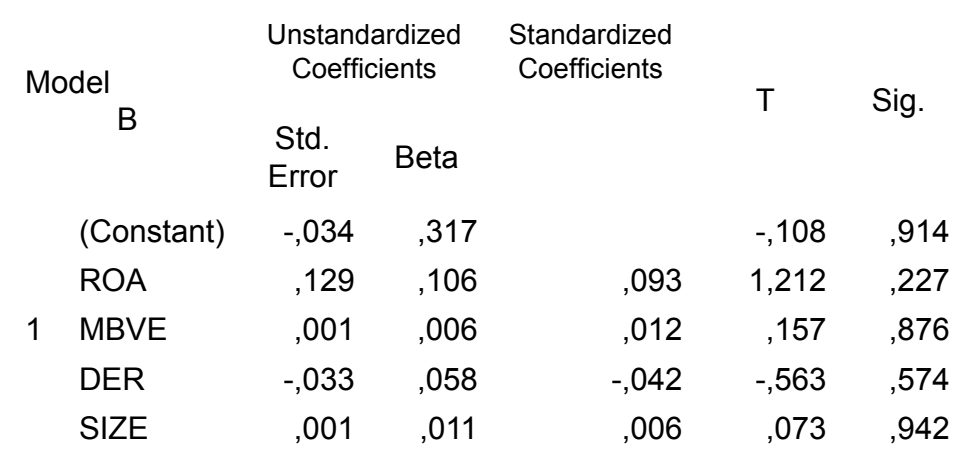

a. Dependent Variable: Unstandardized Residual

Sumber: Output SPSS, data sekunder diolah, 2019

sebesar 25,011 nilai maksimum size sebesar 33,473. Rata-rata (mean) size sebesar 29,141 dengan standar deviasi sebesar 2,015. Hasil nilai standar deviasi lebih kecil dari nilai rata-ratanya yang menunjukan bahwa variabel size tersebut memiliki sebaran yang tidak terlalu besar.

\section{Variabel Dependen}

Variabel DPR/Y nilai minimum 0,023 perusahaan secara keseluruhan membayar deviden terendah $\operatorname{Rp~2,23~dan~tertinggi~}$ Rp 99,9. Rata-rata (mean) 0,444, secara keseluruhan perusahan mampu membayar deviden sebesar $\mathrm{Rp} 44,4$. Sedangkan nilai standar deviasi 0,281 lebih kecil menunjukkan bahwa variabel DPR memiliki sebaran yang tidak terlalu besar.

\section{Uji Normalitas}

Pengujian normalitas data menggunakan uji K-S dengan ketentuan $>0,5$. Hasil uji normalitas pada tabel 3. Hasil uji normalitas data didapatkan hasil test statistic sebesar 0,059 , tingkat signifikansi sebesar 0,200 lebih besar 0,05 data telah terditribusi dengan normal.

\section{Uji Multikolinieritas}

Hasil uji multikolinieritas, sebagai berikut:
Tabel 4

Hasil Uji Multikolinieritas Coefficients ${ }^{a}$

\begin{tabular}{cccc}
\hline \multirow{2}{*}{ Model Tolerance } & \multicolumn{3}{c}{ Collinearity } \\
\cline { 3 - 4 } & \multicolumn{2}{c}{ Statistics } \\
\cline { 3 - 4 } & (Constant) & & \\
\multirow{2}{*}{1} & ROA MBVE &, 918 & 1,089 \\
& DER &, 880 & 1,137 \\
& SIZE &, 941 & 1,062 \\
& &, 905 & 1,104 \\
\hline
\end{tabular}

a. Dependent Variable: DPR

Sumber: Output SPSS, data sekunder yang diolah, 2019

Hasil uji statistic menunjukkan tidak terjadi gejala Multikoliniearitas, sebab semua angka VIF dibawah 10 dan tolerance value di atas 0,10 . Nilai VIF terbesar 1,137 lebih kecil dari 10. Sedangkan nilai terkecil dari tolerance value 0,880 yang berarti lebih besar dari 0,10.

\section{Uji Heteroskedastisitas}

Uji heteroskedastisitas menggunakan uji Glejser. Hasil uji Glejser ada pada tabel 5.

Hasil perhitungan tidak ada nilai signifikansi (sig.) <0,05. Maka, disimpulkan bahwa data tidak terdapat gangguan heteroskedastisitas.

\section{Uji Autokorelasi}

Adapun hasil uji Autokorelasi adalah: 
Tabel 6

Hasil Uji Autokorelasi

Runs Test

\begin{tabular}{lr}
\hline & $\begin{array}{c}\text { Unstandardized } \\
\text { Residual }\end{array}$ \\
\hline Test Value &, 01591 \\
Cases < Test Value & 95 \\
Cases >= Test & 95 \\
Value & 95 \\
Total Cases & 190 \\
Number of Runs & 90 \\
Z &,- 873 \\
Asymp. Sig. &, 383 \\
(2-tailed) & \\
\hline
\end{tabular}

Sumber: Data sekunder yang diolah SPSS 23, 2019

Hasil uji autokorelasi menggunakan uji Runs diperoleh nilai Asymp. Sig. (2-tailed) $0,383>0,05$. Hal ini berarti data telah bebas autokorelasi.

\section{Uji Hipotesis Dengan Regresi Berganda}

Pengujian dengan analisis regresi bergandan di dapatkan hasil sebagai berikut:

Dari hasil pengujian, didapatkan persamaan sebagai berikut:

$$
Y=0,438+0,016 X_{1}+0,025 X_{2}-0,158 X_{3}
$$

Berdasarkan persamaan regresi tabel 4.10 dapat diinterpretasikan sebagai berikut:

1. Nilai koefisien / konstanta / intersep sebesar 0.438 jika tidak ada variabel DPR, ROA, MBVE dan DER.

Tabel 7

Analisis Regresi Berganda

Coefficients $^{\mathrm{a}}$

\begin{tabular}{|c|c|c|c|c|c|c|}
\hline \multirow{2}{*}{ Mode } & \multirow{2}{*}{ B } & \multicolumn{2}{|c|}{$\begin{array}{l}\text { Unstandardized } \\
\text { Coefficients }\end{array}$} & \multirow[t]{2}{*}{$\begin{array}{c}\text { Standardized } \\
\text { Coefficients }\end{array}$} & \multirow[b]{2}{*}{$\mathrm{T}$} & \multirow[b]{2}{*}{ Sig. } \\
\hline & & $\begin{array}{l}\text { Std. } \\
\text { Error }\end{array}$ & Beta & & & \\
\hline \multirow[t]{4}{*}{1} & (Constant) & ,438 & ,039 & & 11,198 & ,000 \\
\hline & ROA & ,016 & ,094 & ,012 & , 166 & ,868 \\
\hline & MBVE & ,025 & ,006 & ,320 & 4,591 & ,000 \\
\hline & DER &,- 158 & ,050 &,- 213 & $-3,125$ & ,002 \\
\hline
\end{tabular}

a. Dependent Variable: DPR

Sumber : Data sekunder yang diolah, 2019

Tabel 8

Hasil Uji t

Coefficients $^{a}$

\begin{tabular}{|c|c|c|c|c|c|c|}
\hline \multirow[b]{2}{*}{ Model } & \multirow[b]{2}{*}{ B } & \multicolumn{2}{|c|}{$\begin{array}{c}\text { Unstandardized } \\
\text { Coefficients }\end{array}$} & \multirow[t]{2}{*}{$\begin{array}{c}\text { Standardized } \\
\text { Coefficients }\end{array}$} & \multirow[b]{2}{*}{$\mathrm{T}$} & \multirow[b]{2}{*}{ Sig. } \\
\hline & & $\begin{array}{l}\text { Std. } \\
\text { Error }\end{array}$ & Beta & & & \\
\hline \multirow[t]{4}{*}{1} & (Constant) & ,438 & ,039 & & 11,198 &, 000 \\
\hline & $\mathrm{ROA}$ &, 016 & ,094 & ,012 & , 166 & ,868 \\
\hline & MBVE & ,025 & ,006 & ,320 & 4,591 &, 000 \\
\hline & DER &,- 158 & ,050 &,- 213 & $-3,125$ & ,002 \\
\hline
\end{tabular}

a. Dependent Variable: DPR

Sumber: Output SPSS, data sekunder diolah, 2019 


\section{Tabel 9}

\begin{tabular}{|c|c|c|c|c|c|c|}
\hline \multicolumn{7}{|c|}{ Hasil Uji F atau Uji Simultan } \\
\hline \multicolumn{2}{|c|}{ Model } & $\begin{array}{l}\text { Sum of } \\
\text { Squares }\end{array}$ & Df & $\begin{array}{l}\text { Mean } \\
\text { Square }\end{array}$ & $\mathrm{F}$ & Sig. \\
\hline 1 & Regression & 2,285 & 3 & 762 & 11,171 &, $000^{b}$ \\
\hline & Residual & 12,681 & 186 & ,068 & & \\
\hline & Total & 14,966 & 189 & & & \\
\hline
\end{tabular}

a. Dependent Variable: $Y$

b. Predictors: (Constant), X3, X2, X1

Sumber: Data sekunder yang diolah SPSS 23, 2019

2. Nilai koefisien variabel $\operatorname{ROA}\left(\mathrm{X}_{1}\right)$ sebesar 0,016 menunjukkan apabila $R O A$ naik sebesar satu satuan, maka DPR akan cenderung naik sebesar 0,016 dan berlaku sebaliknya, dengan asumsi variabel lainya dalam keadaan konstan.

3. Nilai koefisien variabel MBVE $\left(X_{2}\right)$ sebesar 0,025 menunjukkan apabila MBVE naik sebesar satu satuan, maka DPR akan cenderung naik sebesar 0,025 dan berlaku sebaliknya, dengan asumsi variabel lainya dalam keadaan konstan.

4. Nilai koefisien variabel DER $\left(X_{3}\right)$ sebesar $-0,158$ menunjukkan apabila $D E R$ naik sebesar satu satuan, maka DPR akan cenderung turun $-0,158$ dan berlaku sebaliknya, dengan asumsi variabel lainya dalam keadaan konstan.

\section{Uji t atau Uji Parsial}

Hasil uji t pada model persamaan pertama ada pada tabel 8 .

Pada model persamaan I, diketahui tingkat signifikan $5 \%$ diperoleh nilai $t_{\text {tabel }}$ sebesar 1,973. Pada model persamaan I menunjukkan hasil:

1. Variabel $R O A$ menujukkan nilai $t_{\text {hitung }}$ $0,166<$ nilai $t_{\text {tabel }} 1,653$ dan nilai signifikan sebesar $0,868>0,05$, sehingga $\mathbf{H}_{1}$ Ditolak. Ini berarti ROA secara statistik tidak berpengaruh terhadap perubahan variabel kebijakan dividen (DPR).

2. Variabel MBVE menujukkan nilai $t_{\text {hitung }}$ $4,591>$ nilai $_{\text {tabel }} 1,653$ dan nilai signifikan sebesar $0,000<0,05$, sehingga $\mathbf{H}_{2}$ Diterima. Ini berarti MBVE secara statis- tik berpengaruh terhadap perubahan variabel kebijakan dividen (DPR).

3. Variabel DER menujukkan nilai $t_{\text {hitung }}$ $-3,125<$ nilai $t_{\text {tabel }} 1,653$, nilai signifikan $0,002<0,05$, sehingga $\mathbf{H}_{3}$ Ditolak. Ini berarti variabel DER secara statistik tidak berpengaruh terhadap perubahan variabel kebijakan dividen (DPR).

\section{Uji F atau Uji Simultan}

Uji statistik $F$ menunjukkan apakah semua variabel bebas (independen) yang dimasukkan dalam model mempunyai pengaruh secara bersama-sama terhadap variabel terikat (dependen). ada pada tabel 9.

Hasil analisis didapatkan $F_{\text {Hitung }} 11,171$ $>F_{\text {Tabel }} 0,1170$ taraf signifikansinya 0,000 . Maka disimpulkan angka signifikan sebesar 0,000 lebih kecil dari 0,05. Maka kesimpulannya adalah $\mathrm{H}_{\mathrm{o}}$ ditolak dan $\mathrm{H}_{\mathrm{a}}$ diterima. Artinya bahwa variabel ROA, MBVE, DER secara bersama-sama berpengaruh terhadap DPR.

\section{Koefisien Determinan $\left(\mathbf{R}^{2}\right)$}

Hasil uji nilai koefisien determinasi seperti pada tabel 10.

Hasil perhitungan koefisien determinasi (Adjusted $R$ Square) sebesar 0,139 bahwa $13,9 \%$ variabel kebijakan dividen tunai dapat dijelaskan oleh Profitabilitas, Investment Opportunity Set, Leverage. Sedangkan sisanya sebesar $86,1 \%$ dijelaskan oleh variabel lain diluar model penelitian. 
Tabel 10

Hasil Uji Koefisiensi Determinasi

Model Summary

\begin{tabular}{lc|r|r|r|l}
\hline Model & $\mathrm{R}$ & $\begin{array}{c}\mathrm{R} \\
\text { Square }\end{array}$ & $\begin{array}{c}\text { Adjusted } \\
\mathrm{R} \text { Square }\end{array}$ & $\begin{array}{c}\text { Std. Error } \\
\text { of the } \\
\text { Estimate }\end{array}$ & $\begin{array}{l}\text { Durbin } \\
\text { Watson }\end{array}$ \\
\hline 1 &, $391^{\mathrm{a}}$ &, 153 &, 139 &, 2611066 & 1,616 \\
\hline
\end{tabular}

a. Predictors: (Constant), X3, X2, X1

b. Dependent Variable: $Y$

Sumber: Data sekunder yang diolah SPSS 23, 2019

Tabel 11

Hasil Uji Moderasi

(Moderated Regression Analysis)

Coefficients $^{a}$

\begin{tabular}{|c|c|c|c|c|c|c|}
\hline \multirow[b]{2}{*}{ Model } & \multirow[b]{2}{*}{ B } & \multicolumn{2}{|c|}{$\begin{array}{l}\text { Unstandardized } \\
\text { Coefficients }\end{array}$} & \multirow{2}{*}{$\begin{array}{c}\text { Standardized } \\
\text { Coefficients } \\
\text { T }\end{array}$} & \multirow[b]{2}{*}{ Sig. } & \\
\hline & & $\begin{array}{l}\text { Std. } \\
\text { Error }\end{array}$ & Beta & & & \\
\hline \multirow[t]{6}{*}{1} & (Constant) & 451 & ,038 & & & \\
\hline & $\mathrm{X} 1$ & 2,237 & 1,607 & 1,662 & 1,392 & 165 \\
\hline & $\mathrm{X} 2$ & ,022 & ,006, & 284 & 4,037 & ,000 \\
\hline & X3 & $-2,028$ & ,521 & $-2,737$ & $-3,895$ &, 000 \\
\hline & X1_X4 &,- 074 & , 055 & $-1,610$ & $-1,351$ & , 178 \\
\hline & X3_X4 & ,063 & , 017 & 2,535 & 3,607 & 000 \\
\hline
\end{tabular}

Sumber: Output SPSS, data sekunder diolah, 2019

\section{Uji Moderasi}

Hasil perhitungan variabel moderasi didapatkan hasil ada pada tabel 11

Hasil perhitungan moderasi didapatkan hasil persamaan regresi sebagai berikut :

$$
\begin{gathered}
Y=0,451+2,237 X_{1}+0,022 X_{2}-2,028 X_{3}- \\
0,074\left(X_{1}{ }^{*} X_{4}\right)+0,63\left(X_{3}{ }^{*} X_{4}\right)+e
\end{gathered}
$$

Dalam model persamaan pertama penelitian ini diketahui pada tingkat signifikan 0,05 diperoleh nilai $t_{\text {tabel }}$ sebesar 1,653 Berdasarkan Tabel 4.12 model persamaan pertama menunjukkan hasil:

1. Variabel $R^{*} A^{*}$ SIZE diperoleh hasil nilai $\mathrm{t}_{\text {hitung }} 1,351<\mathrm{t}_{\text {tabel }} 1,653$ signifikan 0,178 $>0,05$, sehingga $\mathbf{H}_{5}$ Ditolak. Ini berarti variabel Size tidak mampu memoderasi pengaruh profitabilitas terhadap Kebijakan Dividen.

2. Variabel $D^{*}{ }^{*}$ SIZE diperoleh hasil ni- lai $t_{\text {hitung }} 3,607>t_{\text {tabel }} 1,653$ dan nilai signifikan sebesar $0,000>0,05$, sehingga dapat dibuktikan bahwa $\mathbf{H}_{6}$ Diterima. Ini berarti variabel Size mampu memoderasi pengaruh Leverage terhadap Kebijakan Dividen.

\section{Pembahasan \\ Pengaruh Profitabilitas terhadap \\ Kebijakan Dividen \\ Profitabilitas berupa kelebihan penghasilan diatas biaya selama satu periode akuntansi, dan profitabilitas telah menjadi penentu kebijakan dividen selama bertahun-tahun Badu (2013), hal ini, menjadikan profit sebagai faktor penting yang berpengaruh. Namun, hasil penelitian ini Profitabilitas yang diproksi ROA menunjukan tidak memiliki pengaruh}


terhadap kebijakan devidend.

Hal ini sejalan hasil penelitian Rizqia, Aisjah, Sumiati (2013); dan Kannadhasan, et.al (2017) yang menyatakan bahwa profitabilitas tidak berpengaruh terhadap kebijakan dividen. Namun, tidak mendukung hasil penelitian Mubarok (2016).

Tidak berpengaruhnya variabel Profitabilitas terhadap Kebijakan deviden, dimungkinkan:

1. Perusahaan memperoleh laba, namun tidak dibagikan kepada pemegang saham, hal ini dimungkinkan adanya pengenaan pajak $10 \%$ dari dividend yang diterima sehingga hasil yang diterima investor lebih rendah. Berbeda dengan investor yang ingin menjual sahamnya hanya dikenakan PPh sebesar 5\%. Hal ini sesuai Tax Preferency Theory dari Farrar and Slewyn (1967) dan Brennan (1970) menjelaskan bahwa investor lebih menyukai retained earnings daripada dividend, karena pertimbangan pajak yang dikenakan kepada capital gain lebih rendah. Pada teori ini, perusahaan agar membayar dividend yang lebih rendah jika ingin memaksimalkan harga sahamnya.

2. Perusahaan memperoleh laba, namun keputusan manajemen memaksimalisasi pendanaan internal guna operasional dan pengembangan perusahaan agar keuangan perusahaan efisien, hal ini sesuai dengan teori The pecking order theory, perusahaan akan menggunakan sumberdaya keuangan internal perusahaan, untuk efisiensi keuangan, (Myers 1984, Myers and Majluf 1984).

Di Indonesia perusahaan dengan karakteristik seperti ini adalah Lippo Cikarang (LPCK) karena strategi perusahaan yang terus melakukan ekspansi.

3. Perusahaan mengalami kerugian, namun tetap membayar devidend. Hal ini sejalan dengan teori signal yakni perusahaan memberikan sinyal positif melalui pembagian dividend, sehingga investor mengetahui adanya peluang investasi pada masa depan yang lebih menjanjikan bagi nilai perusahaan (Jogiyanto Hartono, 1998). Sehingga, perusahaan yang membayar devidend akan berkomunikasi dengan pasar.

Hasil penelitian sejalan dengan penelitian Rizqia, Aisjah, Sumiati (2013) dan Kannadhasan, et.al (2017), yang menyatakan bahwa profitabilitas tidak berpengaruh terhadap kebijakan dividen. Namun, penelitian ini tidak mendukung hasil penelitian Mubarok (2016). Bhattacharya, (1979), John and Williams (1985), dan Miller and Rock, (1985), bahwa pembayaran dividend merupakan informasi dan dapat dipergunakan sebagai alat pemberi isyarat untuk mempengaruhi harga saham.

Pada perusahaan manufaktur di Indonesia yakni PT Indomobil Sukses (IMAS) di tahun 2018 mengalami kerugian sebesar Rp $64 \mathrm{M}$ tetapi tetap membayar devidend tunai sebesar $R p$ 13,82 M atau setara dengan Rp 5/saham. Keputusan ini diambil memalui RUPST dimana dana untuk membayar deviden tersebut berasal dari laba ditahan tahun- tahun sebelumnya yang nilainya Rp 1,4 T. (Kontan, 28 Juni 2018).

\section{Pengaruh Investment Opportunity Set terhadap Kebijakan Dividen}

Investment opportunity set adalah nilai perusahaan yang besarnya tergantung pada pengeluaran yang ditetapkan manajamen di masa datang, yang pada saat ini merupakan piihan-pilihan investasi yang diharapkan akan mengahsilkan return yang lebih besar (Gaver and Gaver, 1993).

Pembayaran dividend oleh perusahaan akan memberikan signal positif kepada pasar, dengan harapan bahwa investor akan memberikan penilaian terdapat peluang investasi yang lebih baik. Hal ini, sejalan dengan teori signal, bahwa perusahaan memberikan sinyal positif melalui pembagian dividen, (Jogiyanto Hartono, 1998).

Perusahaan yang membayar devidend akan memberikan informasi kepada pasar. 
Pembagian dividend merupakan isyarat, sesuai dengan model-model pemberian isyarat (Bhattacharya, 1979, John and Williams, 1985, dan Miller and Rock, 1985), bahwa pembayaran dividend berisi informasi dan oleh karenanya dapat digunakan sebagai alat pemberian isyarat untuk mempengaruhi harga saham.

Penelitian ini sejalan dengan penelitian Rizqia, Aisjah, Sumiati (2013); Bostanci, Kadioglu and Sayilgan (2018) dan Rafindadi and Bello (2019) yang meyatakan bahwa IOS berpengaruh terhadap kebijakan dividend. Namun, penelitian ini tidak mendukung hasil penelitian yang dilakukan Ravichandran (2011).

\section{Pengaruh DER terhadap Kebijakan Dividen}

Debt to Equity Ratio (DER) merupakan rasio untuk mengukur proporsi dana yang bersumber dari utang untuk membiayai aktiva perusahaan (Sudana, 2011). Semakin besar utang, akan berakibat menurunnya kemampuan perusahaan untuk membayar dividend, hal ini dikarenakan perusahaan harus menyediakan sejumlah dana yang relatif tetap untuk membayar utang.

Uji statistic didapatkan bahwa variabel DER berpengaruh negative signifikan terhadap DPR, hal ini dimungkinkan:

1. Perusahaan memiliki struktur aktiva yang tinggi dan cenderung stabil. Sehingga perusahaan tidak perlu mengambil resiko dengan mengambil utang untuk membiayai dividend. Karena perusahaan sudah mampu membayar dividend dari laba yang diperolehnya. Maka, perusahaan tidak perlu lagi menggunakan utang untuk menutup dividend yang akan dibayarkan kepada para investor yang ada di perusahaan tersebut. Selain itu tingginya struktur aktiva yang dimiliki perusahaan menunjukkan bahwa perusahaan dalam kondisi stabil dan tidak memerlukan level utang yang tinggi. Hal ini sejalan dengan The Pecking Order Theory, dimana perusahaan akan menggunakan sumberdaya keuangan internal, guna efisiensi keuangan, (Myers 1984, Myers and Majluf 1984).

2. Namun apabila perusahaan tetap membayarkan dividend, setelah dana-dana untuk investasi tercukupi, tetapi masih ada "pendapatan sisa" atau pendapatan residual, dividend akan dibayarkan. Maka, pendekatan yang tepat adalah teori dividend residual atau residual dividend theory (Martin et al., 1994).

Penelitian ini menolak hasil penelitian Rizqia, Aisjah, Sumiati (2013); Mubarok (2016) dan Rafindadi and Bello (2019) namun sejalan dengan hasil penelitian Bostanci, Kadioglu and Sayilgan (2018) dan Kannadhasan, et al (2017).

\section{Pengaruh ROA terhadap DPR dengan dimoderasi Size}

Size sebagai variabel moderasi mempelemah variabel ROA terhadap DPR. $\mathrm{Hal}$ ini dimungkinkan, bahwa perusahaan yang dijadikan sampel penelitian merupakan perusahaan-perusahaan besar sehingga pendanaan untuk operasional perusahaan dan kegiatan investasi juga besar, sehingga variabel ROA yang di tunjukkan oleh Size memperlemah peran ROA terhadap DER.

\section{Pengaruh DER terhadap DPR dengan dimoderasi Size}

Size sebagai variabel moderasi memperkuat variabel DER dengan DPR. $\mathrm{Hal}$ ini, perusahaan yang dijadikan sampel penelitian memilih kebijakan utang (DER) untuk mencapai struktur modal yang optimal. Struktur modal yang optimal akan memberikan keleluasaan bagi perusahaan dalam menentukan strategi perusahaan untuk meningkatkan nilai perusahaan. Apabila nilai perusahaan meningkat maka pembayaran dividendpun cenderung meningkat. Manajemen memberikan tanda positif pada pasar melalui pembagian dividend, dengan harapan investor dapat mengetahui bahwa adanya peluang investasi di masa depan yang lebih menjanjikan bagi nilai perusahaan (Jogiyanto Hartono, 1998).

Hasil penelitian ini mendukung teori signal, dimana perusahaan menyampaikan informasi kepada pasar, sejalan dengan model-model pemberian isyarat (Bhattacharya, 1979, John and Williams, 1985, dan Miller and Rock, 1985) pembayaran dividend, merupakan informasi yang digunakan sebagai alat 
pemberian isyarat guna mempengaruhi harga saham. Hasil penelitian ini menolak hasil penelitian Rizqia, Aisjah, Sumiati (2013) namun sejalan dengan hasil penelitian Kannadhasan, et al (2017) dan Maladjian and Khoury (2014),

Size sebagai variabel moderasi memperkuat variabel DER dengan DPR. Hal ini, perusahaan yang dijadikan sampel penelitian memilih kebijakan hutang (DER) untuk mencapai struktur modal yang optimal. Struktur modal yang optimal akan memberikan keleluasaan bagi perusahaan dalam menentukan strategi perusahaan untuk meningkatkan nilai perusahaan. Apabila nilai perusahaan meningkat maka pembayaran devidenpun cenderung meningkat. Manajemen memberikan sinyal positif melalui pembagian dividen, sehingga investor mengetahui bahwa terdapat peluang investasi di masa depan yang menjanjikan bagi nilai perusahaan (Jogiyanto Hartono, 1998).

Hasil temuan ini mendukung teori signal dimana perusahaan menyampaikan informasi ini kepada pasar. Menurut modelmodel pemberian isyarat (Bhattacharya, 1979, John dan Williams, 1985, dan Miller dan Rock, 1985) pembayaran dividen berisi informasi dan oleh karenanya dapat digunakan sebagai suatu alat pemberian isyarat untuk mempengaruhi harga saham. Hasil penelitian ini menolak penelitian yang dilakukan oleh Rizqia, Aisjah, Sumiati (2013) dan namun sejalan dengan penelitian $M$ Kannadhasan, et al (2017) dan Maladjian \& Khoury (2014),

\section{KESIMPULAN DAN SARAN}

Kesimpulan yang bisa diambil, adalah sebagai berikut:

1. Hasil penelitian menyatakan variabel Profitabilitas (ROA) tidak berpengaruh terhadap Kebijakan Dividend Tunai. H1 artinya bahwa ditolak.

2. Hasil penelitian menyatakan MBVE berpengaruh terhadap Kebijakan Dividend Tunai. $\mathbf{H 2}$ artinya bahwa diterima
3. Hasil penelitian menyatakan DER tidak berpengaruh terhadap Kebijakan Dividend Tunai. H3 artinya bahwa ditolak

4. Hasil penelitian menyatakan Size tidak mampu memoderasi pengaruh variabel profitabiltas terhadap kebijakan dividend. H4 artinya bahwa ditolak

5. Hasil penelitian menyatakan Size mampu memoderasi pengaruh variabel $L e-$ verage terhadap kebijakan dividend. H5 artinya bahwa diterima

\section{Saran}

(1). Perusahaan agar memperluas dan meningatkan investasi, untuk memaksimalkan laba dimasa datang sehingga dividend yang dibagikan menjadi lebih tinggi. (2). Hasil penelitian menunjukkan nilai $R^{2}$ sebesar $13,9 \%$. Berarti terdapat $86,1 \%$ variabel lain yang tidak diteliti dapat menjelaskan variabel kebijakan dividen. Sehingga, pada penelitian selanjutnya dapat menambah atau mengganti variabel yang diteliti dengan variabel lainnya. (3). Pada penelitian yang akan datang dapat digunakan objek penelitian berbeda dengan penelitian ini agar dapat menganalisis kebijakan dividend, lebih kompleks seperti pada kompas 100, indeks LQ45 dan Jakarta Islamic Indeks. (4). Bagi perusahaan yang listing di BEI, tidak hanya memfokuskan pada keuntungan saja tanpa melihat kesejahteraan pemegang saham dengan tidak membagikan dividend. (5). Bagi Investor sehrusnya memikirkan berbagi faktor yang dapat mempengaruhi kebijakan dividend seperti, profitabilitas, IOS, rasio hutang serta ukuran perusahaan.

\section{Agenda Penelitian Yang Akan Datang \\ Adanya keterbatasan penelitian maka penelitian selanjutnya perlu dilakukan perbaikan agar hasilnya menjadi lebih baik maka untuk penelitian selanjutnya perlu, Menambah variabel lain yang berpengaruh terhadap variabel dependen (Kebijakan Dividend) seperti struktur kepemilikan, pertumbuhan perusahaan, nilai perusahaan .}




\section{DAFTAR PUSTAKA}

Ahmad, Hira. (2019). Determinants of dividend policy: A study about the impact of changing firm characteristics on dividend payout ratios. Thesis. Master of Financial Economics Candidate University of Western Ontario

Ariandani, P. S. dan Yadnyana, I. K. (2016). Likuiditas Memoderasi Pengaruh Profitabilitas dan Investment Opportunity Set (IOS) Pada Kebijakan Dividen. ISSN: 2302-8556. Vol 17 No 1

Badu, E. A. (2013). Determinants of Dividend Payout Policy of listed Financial Institutions in Ghana. Research Journal of Finance and Accounting Vol.4, No.7. Presbyterian University College, Ghana

Bhattacharya. N. (2007), "Dividend Policy: A Review”. Managerial Finance. Vol. 1: 4-13.

Brealey, R. and S. Myers (2005), Principles of Corporate Finance, 8 th edn. London: McGrawHill.

Brennan, M (1970), "Taxes, Market Valuation and Corporate Financial Policy". National Tax Journal, pp. 417-427.

Brigham, E.F. and Gapenski, L. C. (1996). Intermediate Financial Management. Fifth Edition. Sea Harbor Drive: The Dryden Press.

Brittain, J. A. (1964). "The tax structure and corporate dividend policy." American Economic Review (Papers and Proceedings), Vol. 54 (3).

Cheng Z. C. C, and Zhang J. (2014). Free Cash Flow, Growth Opportunities, and Dividends: Does Cross-Listing of Shares Matter? The Journal of Applied Business Research. 30 (2) : 587598.

Denis, D. J., and Egor, O. (2007), "Why Do Firm's Pay Dividends? International Evidence on the Determinants of Dividend Policy". Electronic copy available at: $\underline{h t t p: / / s s r n . c o m / ~}$ abstract $=887643$

Fama, E. F., and French, K.R. (1998), "Taxes, Financing Decision, and Firm Value". The Journal of Finance, Vol LIII, No.3: June, pp. 819 - 843.

Farinha, J, "Dividend Policy, Coporate Governance and the Managerial Entrenchment Hypothesis: an Empirical Analysis", Journal of Financial Research, 2002.

Farrar, D., and Selwyn, L. (1967),"Taxes, Corporate Financial Policy dan Return to Investors". National Tax Journal, (Desember). pp. 444-454.

Gaver, Jennifer J., \& Kenneth M. Gaver (1993),"Additional Evidence on the Association between the Investment Opportunity Set and Corporate Financing, Dividend, and Compensation Policies," Journal Of Accounting \& Economics, 16:125- 160

Ghozali, Imam. (2011). Aplikasi Analisis Multivariate Dengan Program Ibm Spss 19. Semarang: Badan Penerbit Undip.

Jogiyanto Hartono (1998). Teori Portofolio dan Analisis Investasi, BPFE, Yogyakarta.

John, K., and Williams (1985), "Dividends, Dilution, and Taxes: A Signaling Equilibrium," Journal of Finance, Vol. 40: pp. 1053-1070.

Kannadhasan, S Aramvalarthan, P.Balasubramanian, Gopika, Aishwarya (2017). Determinants of Dividend Policy of Indian Manufacturing Companies: Panel Autoregressive Distributed Lag Analysis. Academy of Accounting and Financial Studies Journal Volume 21, Number 2, 2017.

Kester, V., (1986). Capital and Ownership Structure: A comparison of United States and Japanese Manufacturing Corporations. Financial Management, (Spring), 5-16

Khasmir. 2014. Analisis Laporan Keuangan. Depok: Khrarisma Putra Utama Offset.

Kontan, 28 Juni 2018

Peran Size dalam Memoderasi 
Kristanti. F. T. and Fitrianingsih (2013). The Effect of Profitability and Investment Opportunity Set on Cash Dividend with Liquidity as Moderate Variables. (Studied at Kompas 100 that listed on JSX in 2008-2012 period). Jurnal Manajemen Bisnis Indonesia. Volume 1, Nomor 1, Oktober 2013.

Lintner, J. (1956), "Distribution of Incomes of Corporations among Dividends, Retained Earnings and Taxes". American Economic Review, Vol. 46: pp. 97-113.

Miller, M., and Scholes (1982), "Dividends and taxes: empirical evidence". Journal of Political Economy, Vol. 90: pp. 1118-1141.

Miller, M., and Rock (1985), "Dividend Policy under Asymmetric Information". Journal of Finance, Vol. 40: pp. 1031-1051.

Miller, M, adn M. Scholes (1978), "Dividends and taxes". Journal of Financial Economics, Vol. 6: pp. 333-264.

Mubarok, Nurul (2016). Pengaruh Current Ratio, Debt to Equity Ratio, Total Asset Turnover dan Return on Asset Terhadap Dividend Payout Ratio Pada Perusahaan Sektor Industri Barang Konsumsi Yang Terdaftar Di BEl. I-Finance Vol. 2. No. 2 Desember 2016

Myers, S.C., Majluf, N.S., (1994). Financing and Investment Decisions When Firms have Information that Investors do not have. Journal of Financial Economics, 13, 187-221.

Myers, S.C, (1984). The Capital Structure Puzzle. Journal of Finance, 39 (3), 575-592.

Naceur, S.B., Mohamed, G., and Amel, B., (2006), "On the Determinants and Dynamics of Dividend Policy". International Review of Finance, Vol. 6. No. 1-2: pp. 1-23.

Nathani, Navita and Gangil. Ritu. (2019). Determinants of Dividend Policy in Indian Companies: A Panel Data Analysis. Article in SSRN Electronic Journal January 2019: 570-587

Ravichandran, S. Devi, Susela and Marimuthu, Maran (2011) Investment opportunity set and dividend policy in Malaysia. Full Length Research Paper African Journal of Business Management Vol. 5(24), pp. 10128-10143, 14 October, 2011. ISSN 1993-8233 @2011 Academic Journals. Available online at http://www.academicjournals.org/AJ BM. DOI: 10.5897/AJBM11.687

Rizqia, DA, Aisjah, S, Sumiati (2013), Effect of Managerial Ownership, Financial Leverage, Profitability, Firm Size, and Investment Opportunity on Dividend Policy and Firm Value. Reseach Journal of Finance and Accounting. ISSN 2222-1697 (Paper) ISSN 2222-2847 (Online). Vol.4, No.11, 2013.www.iiste.org.

Rozeff, M.S., (1982). Growth, Beta and Agency Costs as Determinants of Dividend Payout Ratios. Journal of Financial Research 5(3), 249-259.

Sudana (2011). Manajemen Keuangan Perusahaan Teori dan Praktik. Jakarta: Erlangga

Sugiyono. (2013). Metodologi Penelitian Bisnis. CV. Bandung: Alfabet. 
